\title{
Educação ambiental para a escola básica: \\ contribuições para o desenvolvimento da cidadania e da sustentabilidade
}

\author{
HEBERT KONDRAT \\ Instituto de Botânica de São Paulo, \\ São Paulo, SP, Brasil \\ MARIA DELOURDES MACIEL \\ Universidade Cruzeiro do Sul, \\ São Paulo, SP, Brasil
}

\section{DESENVOLVIMENTO HUMANO, DEGRADAÇÃO AMBIENTAL E EDUCAÇÃO AMBIENTAL}

A espécie humana, em seu próspero desenvolvimento, revolucionou o seu modo de vida com novas descobertas e tecnologias, grandes revoluções apenas possíveis em virtude de seu empenho, de sua crescente sabedoria, organização e, mais que tudo isso, de sua integração e relação com o meio ambiente. Com a preservação do equilíbrio dinâmico da natureza, o ser humano foi capaz de crescer e explorar o mundo. Contudo, ao longo de suas conquistas, o homem foi perdendo a noção de sua integração com o meio ambiente, adquirindo uma consciência mais individualista (Guimarães, 1995) e adotando maneiras de desenvolvimento um tanto insustentáveis, relacionadas ao esgotamento de recursos ambientais, à poluição e ao contínuo processo de degradação ambiental (Brasil, 1995; Pino, 2008).

Para que se inicie um processo de mudanças visando ao fim dessa degradação ambiental, é necessário inovações tanto na forma de pensar do homem quanto na sua forma de entender e vivenciar um mundo natural (Sato, 2001). É necessária a 
criação de um novo modelo de desenvolvimento - ou até mesmo a reformulação do já existente - que integre a economia, a sociedade e o meio ambiente, resultando em melhores relações do homem com o ambiente, e consequentemente na melhoria de sua qualidade de vida (Dias, 1994). A transformação da sociedade atual em uma sociedade sustentável depende de uma educação que busque a formação para a cidadania e resulte em uma igualdade de riquezas e em boas condições de vida para todas as gerações (Sader, 1992 apud Pelicione, 1998, p. 29; Santos, 2005).

A educação ambiental sustenta uma recente discussão sobre as questões ambientais e transformações de conhecimentos, valores e atitudes que devem ser seguidos diante da nova realidade a ser construída, constituindo uma importante dimensão que necessita ser incluída no processo educacional. A educação ambiental é recente e está em constante crescimento, desenvolvendo-se com as práticas cotidianas dos educadores. Ela tem a importante função de atingir toda a população, inclusive as novas gerações, formando cidadãos que possam responder pelo processo de mudanças do atual estado ambiental da Terra. Como a educação tradicional não prepara os indivíduos para a complexa realidade global, a educação ambiental torna-se uma necessidade, um processo contínuo e permanente que deve abranger todos os níveis escolares e etapas da educação formal e informal (Guimarães, 1995).

A educação ambiental é um processo de educação que segue uma nova filosofia de vida, uma nova cultura comportamental que busca um compromisso do homem com o presente e o futuro do meio ambiente. A sua aplicação torna o processo educativo mais orientado para a formação da cidadania. A educação para o desenvolvimento sustentável, como também pode ser chamada, deve considerar as realidades regionais e respeitar as diversidades culturais das populações. Ela deve se constituir basicamente num ensino interdisciplinar, que deve, com o tempo, evoluir para a transdisciplinaridade de todas as matérias do conhecimento, possibilitando com isso um processo de aprendizagem formador de cidadãos capacitados a viver sustentavelmente (Ab'Saber, 1994).

\section{ALFABETIZAÇÃO CIENTÍFICA E A FORMAÇÃO PARA A CIDADANIA: RELAÇÕES ENTRE CIÊNCIA, TECNOLOGIA, SOCIEDADE E AMBIENTE (CTSA)}

Não basta formular ideias para a construção de um novo ideário comportamental humano, é necessário também um estudo aplicativo dessas ideias para que se concretize uma real solução dos problemas ambientais. A sociedade não necessita apenas de consciência, ela precisa também de práticas que ajudem a solucionar os diversos problemas do mundo (Sato, 2001).

"Aprender a vivir es el objeto de la educación, y essa aprendizaje necesita transformar la información en conocimiento, los conocimientos en sapiencia (sabiduría y ciencia) e incorporar essa sapiencia a la vida” (Morim, 2008, p. 35).

Para se concretizar a participação ativa dos cidadãos, é necessário formá-los primeiramente. Para isso é que existe a educação. Para se formar cidadãos ativos, 
aptos a participar de ações de conservação e recuperação do meio ambiente, são requisitados mais que simples conhecimentos populares; são necessários conhecimentos e consciência técnico-científica ligados aos numerosos e complexos processos ambientais (Praia; Gil-Pérez; Vilches, 2007).

Uma alfabetização científica que tenha como base a relação com a sociedade e o meio ambiente torna-se uma exigência para a população. Isso não significa transformar todos os cidadãos em cientistas, mas sim fornecer informações básicas (Gil-Pérez; Vilches, 2004) que permitam a compreensão, por parte dos cidadãos, das possíveis soluções e de suas melhores aplicações (Praia; Gil-Pérez; Vilches, 2007, p. 143). A importância do ensino de ciências é parcialmente demonstrada pela aprendizagem efetiva de conceitos e métodos científicos que auxiliam os futuros cidadãos a enfrentarem as diversas situações de seu dia a dia (Malafaia; Rodrigues, 2008).

Com as críticas aos lados negativos da ciência e pela necessidade de uma educação formadora de cidadãos, capacitados a controlarem socialmente o desenvolvimento da ciência e da tecnologia, novas propostas educacionais foram surgindo. No fim da década de 1960, cria-se uma nova área de estudos, baseada nas relações entre a ciência e a tecnologia (C\&T) com a sociedade, representada pela sigla CTS (Invernizzi; Fraga, 2007).

Com as relações CTS, enfoca-se melhor a função crítica e de responsabilidade do estudo da ciência e da tecnologia, envolvido principalmente em práticas socioambientais. Com um controle da sociedade sobre as atividades da ciência, torna-se possível uma maior democratização das decisões ligadas à C\&T, à sociedade e ao meio ambiente (Farias; Freitas, 2007).

Duas dimensões foram criadas separadamente e partilham uma real necessidade para a presente educação: a educação ambiental e a educação com enfoque CTS. Para a integridade de um ensino de efeito na modificação das atuais relações humanas com o meio ambiente, são necessários mais que simples conceitos ambientalistas, requerem-se também conhecimentos técnicos e científicos ideais para a síntese de críticas e mudanças. A relação C\&T é resultado de relações sociais em um ambiente. A sociedade e o ambiente constituem o espaço de aprendizado, onde se passa e surge a problemática ambiental e social (Ricardo, 2007). Isso explica o porquê da adição, por parte de alguns pesquisadores, de uma nova letra (A) à sigla CTS.

O campo CTS também pode ser tratado como CTSA. A expansão dessa sigla representa o importante impacto socioambiental da educação ambiental no ensino CTS. A educação CTSA é uma poderosa ferramenta que necessita ser reconhecida internacionalmente para que se conquistem todos os objetivos do campo CTS e de uma política científica e tecnológica que busca a modificação do atual desenvolvimento para outro que seja realmente sustentável. $\mathrm{O}$ atual desafio é a integração dessas duas dimensões (educação ambiental e CTS) que devem constituir o mesmo ensino (Invernizzi; Fraga, 2007).

Apesar de muitas ideias a respeito de uma educação CTSA serem estimuladoras de um processo de formação da cidadania, muitos profissionais de ensino ainda oferecem uma grande resistência a elas. Para muitos, a responsabilidade dos assuntos 
ambientais é apenas dos especialistas, cientistas e técnicos formados, que deveriam sozinhos solucionar os diversos problemas do ambiente, que ainda não é considerado coletivo (Vilches; Solbes; Gil-Pérez, 2004). Essa visão individualista, porém, torna-se mais insustentável do que já é quando se observa o atual ensino científico encontrado em diversas instituições educacionais, desde o ensino básico até o superior.

O ensino de ciências ainda não passa de uma simples revisão dos principais conhecimentos já descobertos pelo homem, um modelo de ensino tradicional (Marandino; Ianelli, 2012). O espírito investigativo, de melhorias e descobertas, presente num verdadeiro cientista, e que deve estar presente também no professor de ciências, é perdido ao longo da importante formação dos discentes (Gil-Pérez et al., 1999 apud Praia; Gil-Pérez; Vilches, 2007, p. 147).

Há a necessidade de uma educação CTSA inicial e continuada, que atinja os cursos de graduação, pós-graduação e principalmente de atualização e aperfeiçoamento de docentes, para que esses possam integrar uma consciência ambiental ao tradicional ensino encontrado nas escolas básicas. $\mathrm{O}$ mundo precisa de educadores ambientais que tragam esperança, conhecimento e sabedoria a uma população de cidadãos que devem ser responsáveis pela formação e manutenção de uma sociedade sustentável.

\section{EDUCAÇÃO NÃO FORMAL E O JARDIM BOTÂNICO DE SÃO PAULO}

A educação ambiental não deve ser limitada apenas ao ensino padrão em escolas, ela deve ser um conhecimento público, transmitido e trabalhado por toda pessoa com consciência ambiental. Não apenas por escolas e seus profissionais, mas sim por todos os processos educativos que visem a uma educação para a cidadania (Sato, 2001) como processos de educação não formal.

A educação não formal ocorre em espaços nos quais se realizam intencionalmente processos dinâmicos de aprendizagem, seus objetivos são desenvolvidos ao longo da interação com os envolvidos e é um tipo de educação que motiva os participantes e se adapta ao grupo trabalhado ao longo do processo de ensino (Gohn, 2006). Esse tipo de educação possui certas excentricidades quando comparado com as experiências e atividades de uma escola considerada formal (Fávero, 2007). Ela não se estrutura burocraticamente como a educação formal. A educação formal tem como objetivo básico o ensino-aprendizagem de conhecimentos organizados, separados segundo processos históricos, normas e leis. Por sua vez, a educação não formal possui uma organização distinta de uma escola, ela não é dividida necessariamente por níveis e séries escolares. Muitos de seus objetivos são diferenciados e enriquecidos como consequência do espaço onde se desenvolve o processo educativo. Porém, assim como a educação formal, ela também visa à formação da cidadania por seus meios próprios de trabalho público e coletivo (Gohn, 2006).

Faz parte da educação formal a obtenção de um título acadêmico, um certificado que representa a graduação ao longo da vida acadêmica de um estudante. $\mathrm{Na}$ educação não formal, os resultados nem sempre são verificados, eles acontecem pela 
reflexão dos aprendizes em relação aos seus próprios pensamentos, conhecimentos e atitudes; e podem ser representados por alguns processos como:

Consciência e organização de como agir em grupos coletivos; a construção e reconstrução de concepção(ões) de mundo e sobre o mundo; contribuição para um sentimento de identidade com uma dada comunidade; forma o indivíduo para a vida e suas adversidades (e não apenas capacita-o para entrar no mercado de trabalho); quando presente em programas com crianças ou jovens adolescentes, a educação não formal resgata o sentimento de valorização de si próprio (o que a mídia e os manuais de autoajuda denominam, simplificadamente, como a autoestima); ou seja, dá condições aos indivíduos para desenvolverem sentimentos de autovalorização, de rejeição dos preconceitos que lhes são dirigidos, o desejo de lutarem para ser reconhecidos como iguais (enquanto seres humanos), dentro de suas diferenças (raciais, étnicas, religiosas, culturais, etc.); os indivíduos adquirem conhecimento de sua própria prática, os indivíduos aprendem a ler e interpretar o mundo que os cerca. (idem, p. 30)

Espaços que possuem áreas verdes como jardins botânicos são ambientes propícios para o desenvolvimento da educação não formal e de uma alfabetização científica para a cidadania. São ambientes que naturalmente possuem recursos para o ensino e aprendizagem de ciências e biologia (Vieira; Bianconi; Dias, 2005) com um enfoque CTSA.

Os jardins botânicos têm um forte impacto na conservação e preservação da diversidade biológica. Por meio da educação, eles podem demonstrar a importância da biodiversidade e as consequências de sua desvalorização para o meio ambiente (Willison, 2003) e ainda favorecer maior integração das pessoas ao meio ambiente (Pivelli; Kawasaki, 2005). O desenvolvimento de atividades monitoradas de educação não formal no Jardim Botânico de São Paulo tem tornado o espaço um importante aliado da educação formal (Cerati et al., 2002). Com o propósito de avaliar os conhecimentos prévios de alunos da educação básica visitantes do Jardim Botânico e contribuir com a análise, o desenvolvimento e a aplicação da educação ambiental em um espaço não formal de ensino, foram realizadas atividades monitoradas no espaço do Jardim.

\section{METODOLOGIA}

O estudo foi realizado no Parque Estadual das Fontes do Ipiranga (PEFI). O PEFI, também conhecido como Parque do Estado, é um fragmento florestal com entorno urbanizado localizado no sudeste da cidade de São Paulo, com limite no município de Diadema (Fernandes; Reis; Carvalho, 2002). Possui uma área total de 526,38 hectares e é uma importante reserva biológica da bacia hidrográfica do Riacho Ipiranga, com 24 nascentes de água (Barbosa; Potomati; Peccinini, 2002). O PEFI engloba os seguintes órgãos: Secretaria de Agricultura e Abastecimento; Fundação Parque Zoológico; Centro de Atenção Integrada à Saúde Mental "Dr. 
David Capistrano da Costa Filho" (CAISM); Parque de Ciência e Tecnologia da USP (CienTec); Instituto Geológico (IG); Centro de Esportes, Cultura e Lazer; Centro de Exposições Imigrantes; Centro de Logística e Exportação (CELEX); 97 Distrito de Polícia Militar; 2 Batalhão da Polícia Ambiental do Estado de São Paulo e o Instituto de Botânica (IBt) (São Paulo, 2010).

O IBt é um importante centro de pesquisas que integra a Secretaria do Meio Ambiente. Faz parte dessa instituição o Jardim Botânico de São Paulo, que possui uma área de 36 hectares e ocupa um importante fragmento de Mata Atlântica (Barbosa; Potomati; Peccinini, 2002). O Jardim Botânico de São Paulo é um órgão público que agrega importantes funções a seu espaço, como conservação, pesquisa, educação ambiental e lazer. Ele tem como atração pública córregos, lagos, arboretos, exemplares da flora nativa e exótica, animais habitantes da Mata Atlântica e ainda construções como estufas, casa de pau-a-pique, museu e trilhas. Seu público visitante é constituído por pessoas de diferentes idades e regiões, principalmente por grupos escolares (Cerati et al., 2002).

Dessa forma, foram realizadas atividades monitoradas de educação ambiental para turmas de alunos da escola básica visitantes do Jardim Botânico de São Paulo. A pesquisa classifica-se como observação participante, com registro das falas dos estudantes durante as atividades de monitoria. A observação participante é um tipo de metodologia qualitativa em que o pesquisador participa da realidade da metodologia utilizando-se de sua observação ao mesmo tempo em que interage com os integrantes de sua pesquisa. Essa metodologia, se comparada com a quantitativa, pode se diferir pelo menor número amostral; no entanto, tem a vantagem de extrair resultados mais profundos da pesquisa (Meksenas, 2007).

O tempo que as escolas permaneceram no Jardim Botânico foi bem variado. Assim, as atividades propostas neste trabalho foram realizadas com quatro turmas: duas do $7^{\circ}$ ano do ensino fundamental II, alunos com idade aproximada de 12 anos; e duas do $3^{\circ}$ ano do ensino médio, alunos com idade aproximada de 18 anos; grupos que puderam permanecer na instituição por um tempo mínimo de duas horas e meia.

O tempo foi um fator limitante dos dados, pois, além das abordagens naturais que já são realizadas nas monitorias do Jardim Botânico, foram acrescentadas as abordagens relacionadas à pesquisa, adaptadas ao percurso e ao tempo da visita.

As monitorias foram realizadas em dias diferentes para cada turma, no período matutino, com início às nove horas e término máximo ao meio-dia, o que dependia das características do grupo e das dinâmicas correspondentes. Cada grupo monitorado possuía no máximo vinte alunos.

No início, durante e no final de cada monitoria, foram trabalhadas questões sobre a educação ambiental e cidadania com os alunos. Essas questões eram baseadas em temas que direcionavam as respostas dos alunos aos objetivos do trabalho, por exemplo, o conhecimento prévio deles em relação ao meio ambiente, à educação ambiental, à cidadania e ao Jardim Botânico.

Os temas com as respectivas perguntas elaboradas foram: 
- O motivo da visita - Por que vocês vieram visitar o Jardim Botânico?

- A ideia do ambiente visitado - $\mathrm{O}$ que vocês acham que tem no Jardim Botânico? $\mathrm{O}$ que fazem as pessoas que trabalham aqui?

- A concepção de educação ambiental - $\mathrm{O}$ que vocês entendem por educação ambiental?

- A concepção de cidadania - O que é cidadania?

- A ligação entre educação ambiental e cidadania - Qual a relação entre educação ambiental e cidadania?

- As concepções em relação às plantas - Quais são as partes de um vegetal? Qual a função das flores?

Outras perguntas surgiram ao longo das monitorias, pois as dinâmicas se adaptaram às características do grupo, como a idade e os conhecimentos prévios dos alunos. As respostas foram registradas e categorizadas para a análise dos dados; metodologia abordada por autores como Bardin (1977) e Franco (2003).

Foram criados dois quadros de análise com as categorias e subcategorias organizadas com base nas perguntas realizadas e nas falas dos alunos, respectivamente. Destaca-se que, ao longo das monitorias, inúmeras questões foram trabalhadas, no entanto focou-se a discussão apenas naquelas que envolviam os temas previamente definidos.

Nenhuma informação ou dados sobre a identificação de alunos, professores ou escolas participantes foram apontados no trabalho por questões éticas e de privacidade.

\section{RESULTADOS E DISCUSSÃO}

A seguir encontram-se os resultados obtidos com os alunos do ensino fundamental II e os alunos do ensino médio. As respostas às questões trabalhadas apresentam-se precedidas por EF para os alunos do ensino fundamental e EM para as do ensino médio.

\section{MOTIVO DA VISITA}

- Por que vocês vieram ao Jardim Botânico?

EF: Pelo nosso projeto Aquecimento Global; pra fazer meu relatório; pra conhecer os animais, as plantas; para aprender; porque é educativo; a gente está fazendo herbário.

EM: A professora pediu; para conhecer a floresta; nunca visitei aqui; visitei quando era pequenininha; porque, se eu não viesse, não ganharia nota; vim conhecer; é lindo; é legal; a gente estava vendo negócio de plantas, né?; teve prova ontem; fui mal pra caramba, tava difícil.

Por essa questão inicial, foi possível observar o porquê da visita ao Jardim Botânico por parte dos alunos e, indiretamente, da escola que os levou para esse tipo de atividade. Na categoria Motivo da Visita, as respostas dos alunos do ensino 
fundamental foram divididas nas subcategorias Projeto, Complementação dos Estudos Escolares e Visita Cultural (Figura 1).

Pelas respostas, pôde-se verificar que as escolas foram ao Jardim principalmente para o cumprimento de um objetivo específico, como utilizar o espaço para a realização de um projeto ou mesmo para a complementação dos estudos escolares. As escolas demonstraram expectativas positivas em relação aos recursos existentes no espaço não formal de ensino; recursos que poderiam auxiliar as atividades realizadas na escola, ou seja, subsidiar o ensino formal, como enfatizado por Willison (2003).

Nas respostas dos alunos do ensino médio, observou-se com maior clareza a predominância da subcategoria Complementação dos Estudos Escolares e ainda de duas subcategorias novas, Lazer e Outros (Figura 2). Na resposta "porque, se eu não viesse, não ganharia nota", mesmo que classificada na categoria Outros, é possível identificar um objetivo, ainda que do professor, relacionado às atividades escolares. Já o motivo de visita relacionado à subcategoria Lazer possivelmente resulta da influência de conhecimentos informais proporcionados pela mídia, por exemplo, que geralmente enfatiza a função de lazer dos espaços não formais, entretanto divulga pouco ou nada de suas funções socioambientais, educativas e de pesquisa para a sociedade, como abordado por Pivelli e Kawasaki (2005). No entanto, respostas como "porque é educativo", classificadas na subcategoria Visita Cultural (Figura 1), representaram um conhecimento por parte dos alunos da função educativa do espaço.

Ficou claro que os alunos do ensino médio haviam estudado os conceitos abordados na monitoria, uma vez que afirmaram a cobrança do conteúdo em avaliação escolar. Os alunos também demonstraram conhecimento da importância do estudo em campo para a melhor assimilação das informações, pois, quando explicado que a visita teria um caráter de uma aula em campo, muito mais do que um simples passeio, respostas como "podia ter feito isso antes da prova, né?" foram registradas.

\section{IDEIA DO AMBIENTE VISITADO}

- O que será que tem aqui no Jardim Botânico?

EF: Plantas; vegetais; animais; árvores; biólogos; meio ambiente.

EM: Plantas; flores, briófitas; natureza; muito verde.

- Por que vocês vão ver animais aqui?

EF: Porque eles moram nas plantas.

- Que tipo de animal vocês podem ver aqui?

EF: Macaco; aranha; cobra; tatu-bandeira.

- Só planta?

EM: Não, animais; pessoas; cobras; aves; tem cogumelo; tem um pato ali; patinhos; biodiversidade; muito oxigênio. 
Na categoria Conteúdo do Jardim, as subcategorias Flora, Fauna e Ambiente foram definidas com base nas respostas dos alunos. As primeiras respostas obtidas diziam respeito à flora. O próprio nome da instituição, "Jardim Botânico", provavelmente esteve associado ao direcionamento inicial das respostas dos alunos.

Observou-se também que muitos alunos do ensino fundamental responderam árvores, vegetais e plantas como se fossem diferentes organismos e não como palavras que pudessem designar o mesmo organismo, no caso de vegetais e plantas. Geralmente os alunos atribuíam a palavra vegetal às hortaliças e legumes, e plantas e árvores aos organismos que possuíam dimensões diferenciadas, como o uso da palavra planta para os exemplares pequenos.

Quando discutida a presença de animais no Jardim, observou-se o conceito de habitat dos discentes, que o atribuíram às plantas presentes no espaço. De início, os alunos não tinham a certeza dessa presença, porém, quando questionados e motivados a observarem a mata do lugar, suas ideias e concepções foram surgindo, incentivando-os a uma resposta mais confiante em relação à fauna existente naquele ambiente.

Foi possível notar um processo de observação, tradução de informação visual e utilização de conhecimentos prévios na elaboração das respostas durante a dinâmica da monitoria. Os alunos lançaram mão de conhecimentos prévios adquiridos no próprio processo de aprendizagem que foram essenciais para o esclarecimento e resolução do problema proposto (Giordan; Vecchi, 1996).

Os alunos do ensino médio monstraram respostas mais técnicas, relacionadas a conteúdos abordados nas aulas de biologia, como "briófitas". Isso também foi notado após as perguntas sequenciais, quando os alunos, estimulados, demonstraram a observação do ambiente ao redor e responderam "aves", "cogumelos", termos que representaram maior organização dos seres vivos em grupos e o uso de conhecimentos prévios no diálogo. Conhecimentos adquiridos em séries escolares diferentes, mas que foram resgatados e trabalhados conjuntamente pelos alunos nas atividades de educação não formal (Vieira; Bianconi; Dias, 2005).

- O que fazem as pessoas que trabalham aqui no Jardim Botânico?

EF: Cortam grama; preservam; cuidam das plantas.

EM: Trabalham; cuidam do jardim, dos animais; ajudam a manter o espaço; constroem; estudam biologia; tem instrutor; cuidam da vegetação; estudam; plantam; pesquisa.

- Será que é só preservação? O que mais tem aqui, o que se faz aqui, fora a preservação?

EF: (ninguém respondeu)

- $\mathrm{O}$ que é que tem muito aqui?

EF: Plantas. 
- O que será que tem de interessante nessas plantas?

EF: Flores; frutas.

- Para a gente falar o que tem de interessante, a gente tem que fazer o quê??

EF: Observar.

- Essa parte de observação entra na área de pesquisa (comentou-se com os alunos a existência de centros de pesquisa e de muitos pesquisadores próximos ao Jardim Botânico desenvolvendo inúmeros estudos sobre as plantas).

- Por que é interessante a gente estudar?

EF: Pra saber mais coisas; sobre as plantas.

- Para conhecer o que tem de especial em uma planta, saber qual o seu papel no meio ambiente.

- O que mais? Do que vocês estão participando aqui hoje?

$\mathrm{EF}$ : (ninguém respondeu)

- Por que é importante as pessoas conhecerem?

EF: Para elas colaborarem e ajudarem o meio ambiente.

- Mas para isso elas precisam de quê?

EF: Saber mais.

Pela análise das respostas dos alunos do ensino médio, distinguiram-se diversas atividades atribuídas aos funcionários do Jardim Botânico. Indiretamente, foi possível relacionar as respostas dos alunos aos principais objetivos da instituição, segundo Cerati et al. (2002), como a conservação (cuidam do jardim, dos animais; ajudam a manter o espaço), a pesquisa (estudam biologia; pesquisa) e o ensino (tem instrutor) (Figura 2).

Durante a dinâmica com os alunos do ensino fundamental, foram feitas diferentes perguntas, sequenciais, para que o grupo participasse e perdesse a timidez. Os alunos foram questionados sobre suas respostas para que se motivassem a refletir sobre elas. Eles responderam positivamente à provocação, demonstrando a elaboração de conhecimentos por meio da mediação realizada (Marandino; Ianelli, 2012) e respostas também relacionadas às principais funções do Jardim Botânico destacadas por Cerati et al. (2002) (Figura 1). 
Foi percebido certa surpresa por parte dos discentes quando foi comentado que todos os animais do jardim não estavam presos. Alguns deles nunca haviam tido a oportunidade de conhecer um lugar de mata onde os animais ainda vivessem livres. Todos foram orientados de que os animais ali existentes não estavam confinados, como em um zoológico, mas sim livres, naturalmente, no fragmento de mata ali existente. E que, indiretamente, os animais estavam preservados pela preservação da vegetação ali existente.

O acelerado processo de urbanização tem afastado a natureza do convívio humano (Willison, 2003). Dessa forma, muitos alunos não têm contato com espaços naturais, a maioria deles já nasce no meio urbano, onde o homem domina e tenta controlar tudo. O natural não é conhecido, os animais são confinados em gaiolas, há zoológicos pela cidade, tudo regulado pelo ser humano. Assim, quando alunos visitam um lugar rico em biodiversidade, acreditam que tudo também é manipulado, incluindo os animais.

Comentou-se um pouco sobre os recursos hídricos existentes no Jardim.

- O que tem de diferente nesse córrego quando comparado ao Rio Ipiranga que passa lá perto das construções da cidade?

EF: Tem vitória-régia; flor de lótus.

EM: (silêncio)

- O que tem aqui e não tem lá?

EM: Tem vida; biodiversidade.

- Existem plantas. Se existem plantas, o que mais pode ter?

EM: Peixes.

- Está suja essa água?

EM: Ah, parece; não; tem lodo.

- O que vai às plantas, nas flores?

EM: Caracol; muitos animais; polinizadores.

- O Rio Ipiranga está limpo?

EF: Não, está sujo.

- Por que ele está sujo?

EF: Por causa da poluição; muito lixo; esgoto. 
- Será que tem plantas no Rio Ipiranga?

EF: Não; na cidade, não.

- Por que não?

EF: Porque não tem condições para uma semente nascer; não vai ter gás oxigênio para ela sobreviver.

Quando trabalhadas as questões sobre poluição e meio ambiente com os alunos do ensino médio, tornaram-se aparentes conceitos ecológicos como "biodiversidade" e "polinizadores". Pela observação do objeto de estudo - no caso, o córrego -, os alunos associaram informações visuais locais e conhecimentos prévios que foram úteis para a argumentação e reflexão da questão abordada (Giordan; Vecchi, 1996; Gohn, 2006). Quando questionada a existência de outros organismos nas plantas do córrego, observaram-se também conhecimentos relacionados à interação biológica, fauna e flora, no caso, a polinização.

Os alunos do ensino fundamental observaram a planta aquática ninfeia e a associaram à outra espécie, lembrando principalmente de sua "parente", a vitória-régia (espécies pertencentes à mesma família). Relacionaram as características ambientais (plantas aquáticas) e morfológicas (folhas arredondadas, com grande área de superfície) das espécies, classificando-as indiretamente em um mesmo grupo quando eles as chamaram pelo nome que as conheciam.

Além disso, os alunos utilizaram conhecimentos prévios para a assimilação de informações visuais, demonstrando um processo denominado de aprendizagem significativa durante a atividade (Moreira,1997). Relataram também a ausência de condições para a vida em rios poluídos com base em seus conhecimentos a respeito de rios como o Ipiranga, o Tietê, rios de sua comunidade, destacados frequentemente pela mídia e por outros meios informais, que, segundo Ricardo (2007), complementam a educação escolar e, nesse caso, a educação não formal.

As diferentes respostas fizeram referência a diferentes fontes de conhecimentos, formais, informais e não formais. Durante as reflexões, existiu uma interação entre os conceitos adquiridos de maneira informal e formal, ambos no espaço não formal do Jardim, independentemente do lugar de ocorrência do processo educativo, como abordado por Oliveira e Gastal (2009).

\section{CONCEPÇÕES EM RELAÇÃO ÀS PLANTAS}

- Quais são as partes de um vegetal?

EF: Raiz; caule; folhas; frutos; flores; pólen.

EM: Se eu soubesse, eu colocava na prova; raiz; caule; folha; pétalas; flor; fruto; semente. 
- Qual a função das flores?

EF: Para uso de outros animais, como a abelha, que retira o pólen das flores para fazer o mel; a borboleta come a flor; não, a lagarta come; serve para reproduzir as plantas; proteção.

EM: A “boniteza”; para tudo isso aí; reprodução.

- Por que as flores são coloridas?

EF: Para chamar a atenção dos pássaros; dos polinizadores.

EM: Ela atrai os insetos.

- Por que ela precisa atrair esses animais?

EM: Para eles fazerem a polinização.

$-\mathrm{O}$ animal vai fazer o que na flor?

EF: Pegar o pólen; o néctar; pegar os grãos de pólen.

EM: Se alimentar; o pólen; o néctar.

As respostas demonstraram que a maioria dos alunos organizava as partes de um vegetal separando-as em órgãos (raiz, caule, folhas, flores, frutos, sementes); porém, houve também a colocação de "pólen", que já estava indiretamente incluída na resposta do aluno que disse "flor". Quando questionados se as plantas possuíam alguma importância, um dos alunos disse "oxigênio", resposta também relacionada indiretamente à anterior de um colega que havia dito "fotossíntese". Durante as atividades, a formação dos grupos possibilitou a construção conjunta dos conhecimentos, o que foi percebido quando as respostas dos alunos se complementaram e se relacionaram diretamente ou indiretamente, representando um resultado da atividade coletiva (Gohn, 2006).

Quando trabalhadas as questões sobre a importância das plantas, percebeu-se, no geral, uma visão utilitarista dos vegetais. Segundo Reigota (1999 apud Portela; Braga; Ameno, 2010, p. 332), essa é uma visão antropocêntrica, como se as plantas fossem exclusivas para o uso humano. Isso resulta da falta de conhecimento da planta em si.

Muitos alunos relacionaram diversos fatores à função de uma flor, mas apenas um aluno relacionou à reprodução desses organismos. A maioria deles conhecia o processo de polinização, mas não o entendia, o que pode ter influenciado na presença de alguns erros conceituais. Os alunos não relacionaram a presença do animal na flor à alimentação. Quando esse fator era comentado, eles atribuíam principalmente ao pólen a função de alimentação e se esqueciam do néctar. Para alguns alunos, o animal ia pegar o pólen na flor para jogá-lo em outra flor. 
Essas concepções podem ser originadas quando os alunos aprendem que a abelha carrega baldes de pólen, fazendo referência ao mel. A abelha se alimenta também de pólen, fora o néctar, e, como ela é o principal polinizador exemplificado para o processo, erros de senso comum podem resultar da transposição didática, de um distanciamento horizontal do conceito, que frequentemente é utilizado por professores para a facilitação da explicação e entendimento do aluno (Franzolin; Bizzo, 2007).

Após a explicação do processo de polinização, os alunos demonstraram entendimento do processo, fazendo a relação entre a reprodução, as sementes e os frutos às flores. Foi possível notar que os alunos elaboraram os conhecimentos por meio da mediação realizada, caracterizando um processo que foi além da recepção passiva de informações, um processo construtivista em que os alunos foram os sujeitos de sua própria aprendizagem (Marandino; Ianelli, 2012).

\section{CONCEPÇÕES DE EDUCAÇÃO AMBIENTAL, CIDADANIA E SUAS RELAÇÕES}

- Vocês já escutaram falar de educação ambiental?

EF: Sim.

EM: Já.

- O que é educação ambiental? O que vocês entendem por educação ambiental?

EF: Cuidar do meio ambiente; preservar; como preservar; conservar se não um dia acaba; dar valor ao que você tem; reciclar; preservar; aprender sobre o ambiente; educar a natureza.

EM: Respeitar o meio ambiente; aprender sobre ele; preservar; conhecer para depois preservar.

- Por que é importante a educação ambiental?

EF: Para preservar a natureza; para a gente viver.

EM: Para conscientização das pessoas; pra conservar; para preservar; pra vida.

- Por que a gente vai viver mais?

EF: Vai ter mais árvores; oxigênio (um aluno comentou também sobre a sua participação em atividades do SOS Mata Atlântica, como ir a escolas, praias, e os trabalhos com a comunidade que participa).

Nesse momento foi explicado para os alunos um pouco sobre a educação ambiental, que ela é um processo contínuo ao longo da vida das pessoas, e a importância de a comunidade conhecer melhor o meio ambiente para respeitá-lo. 
Os alunos do ensino fundamental estranharam a resposta do colega "educar a natureza". No entanto, ela foi destacada. Pereira e Sauma Filho (2005), em estudo com alunos do ensino fundamental e médio, constataram que $78 \%$ dos discentes estudados não se viam como parte integrada do ambiente, apresentando uma visão reducionista. Segundo Guimarães (1995), muitas pessoas se consideram parte separada da natureza e não possuem uma visão integrada do meio ambiente do qual fazem parte.

Os alunos se referiram à educação ambiental mais como uma atitude, uma qualidade de ser educado, um comportamento; poucos alunos ligaram a educação ambiental a um processo de educação, de orientação das pessoas, como observado nas respostas "aprender sobre o meio ambiente; educar a natureza; conhecer para depois conservar".

A resposta "conservar se não um dia acaba" está relacionada a um comportamento; no entanto, não deixa de estar associada ao processo e objetivos da educação ambiental - que busca um compromisso das pessoas com o presente e com o futuro do meio ambiente (Ab’Saber, 1994) - e à sustentabilidade (Santos, 2005).

Exemplos como "reciclar" "e trabalhos com a comunidade", comentados pelos alunos, relacionam-se ao uso da ciência e tecnologia pela sociedade para o controle do lixo no ambiente, no primeiro exemplo, e para um trabalho de educação ambiental no segundo exemplo. Ou seja, exemplificações de práticas socioambientais associadas ao estudo da ciência e tecnologia envolvidas em relações CTS (Farias; Freitas, 2007).

Quando questionada a importância da educação ambiental, verificaram-se respostas relacionadas à função educativa e à cidadania. Respostas como "para conscientização das pessoas; para preservar a natureza" se relacionam ao processo de alfabetização, de capacitação, necessários para a participação ativa dos cidadãos em práticas de preservação ambiental (Praia; Gil-Pérez; Vilches, 2007).

- O que é cidadania? O que vem à cabeça quando falamos de cidadania?

EF: Ser legal com o próximo; cidade; respeitar; população; os deveres de uma população.

EM: Respeitar o próximo; você respeitar mais; dia a dia; respeito da sociedade; respeito pelo ambiente.

- Quem é esse próximo?

EM: O meio ambiente; a natureza.

- Qual a relação entre educação ambiental e cidadania?

EF: A educação ambiental é para se conscientizar, para cuidar da natureza. Ter respeito pela natureza entra na parte da cidadania, entra nos deveres que você tem; da maneira que o ser humano vai ter seus direitos e deveres, a natureza 
também; na cidadania, você tem seus deveres e, como é uma educação ambiental, você tem o dever de cuidar; se o cidadão tem seus direitos, por que as plantas também não?

EM: Cidadania é o dever, são os deveres e direitos que você tem na sociedade, envolve a educação ambiental, a preservação do meio ambiente; educação ambiental é o fato de preservar; respeito das pessoas pela natureza; educação ambiental é o dever que você tem que preservar.

Quando se trabalhou o conceito de cidadania, pôde-se verificar certa dificuldade de os alunos conceituá-la; no entanto, importantes relações puderam ser notadas. Os alunos relacionaram o respeito como um dever pertencente à cidadania e a conscientização e preservação do meio ambiente à educação ambiental. Observou-se uma ideia de alfabetização científica relacionada ao processo de conscientização abordado pelos alunos. Um processo de aprendizado para a cidadania relacionado à capacitação das pessoas para a manutenção da natureza, "para cuidar da natureza”, segundo os alunos. Uma formação para uma vida sustentável (Ab’Saber, 1994) com base em uma boa relação com a sociedade ("com o próximo") e o meio ambiente (“com a natureza; com as plantas”) (Praia; Gil-Pérez; Vilches, 2007).

\begin{tabular}{|c|c|c|}
\hline Categorias & Subcategorias & Exemplos observados \\
\hline \multirow{3}{*}{$\begin{array}{l}\text { Motivo da } \\
\text { Visita }\end{array}$} & Projeto & Aquecimento global \\
\hline & $\begin{array}{l}\text { Complementação } \\
\text { dos Estudos } \\
\text { Escolares }\end{array}$ & Pra fazer meu relatório; a gente está fazendo herbário \\
\hline & $\begin{array}{l}\text { Visita Cultural } \\
\text { (aquisição de novos } \\
\text { conhecimentos) }\end{array}$ & $\begin{array}{l}\text { Para aprender; porque é educativo; pra } \\
\text { conhecer os animais, as plantas }\end{array}$ \\
\hline \multirow{3}{*}{$\begin{array}{l}\text { Conteúdo do } \\
\text { Jardim }\end{array}$} & Flora & Vegetais; árvores; plantas \\
\hline & Fauna & Macaco, aranha, cobra, tatu-bandeira, biólogos \\
\hline & Ambiente & Meio ambiente \\
\hline \multirow{3}{*}{$\begin{array}{l}\text { Funções } \\
\text { do Jardim } \\
\text { Botânico }\end{array}$} & Conservação & Preservam; cuidam das plantas \\
\hline & Pesquisa & Observar \\
\hline & Educação & Pra saber mais coisas; sobre as plantas \\
\hline \multirow{3}{*}{ Plantas } & Estrutura & Raiz; caule; folhas; fruto; flores; pólen; sementes \\
\hline & $\begin{array}{l}\text { Uso Alimentício } \\
\text { e Medicinal }\end{array}$ & Fruto; hortelã; boldo; camomila; chá \\
\hline & $\begin{array}{l}\text { Importância } \\
\text { Ambiental } \\
\end{array}$ & $\begin{array}{l}\text { Fotossíntese; oxigênio; lugar mais fresco; sombra; } \\
\text { eles [animais] moram nas plantas }\end{array}$ \\
\hline \multirow{3}{*}{ Flores } & $\begin{array}{l}\text { Importância } \\
\text { para a Planta }\end{array}$ & Serve para reproduzir as plantas; proteção \\
\hline & $\begin{array}{l}\text { Importância para } \\
\text { os Animais }\end{array}$ & $\begin{array}{l}\text { Para uso de outros animais [abelha]; a borboleta } \\
\text { come a flor; não, a lagarta come; pólen; néctar }\end{array}$ \\
\hline & $\begin{array}{l}\text { Problemas } \\
\text { Relacionados } \\
\text { à sua Falta }\end{array}$ & $\begin{array}{l}\text { Vai diminuir o ar; ela vai morrer; ela é a reprodutora; } \\
\text { não vai ter sementes mais; não vai ter o fruto; não } \\
\text { vai ter a reprodução; não vai ter morango }\end{array}$ \\
\hline
\end{tabular}


(...continuação)

\begin{tabular}{|l|l|l|}
\hline Categorias & \multicolumn{1}{|c|}{ Subcategorias } & \multicolumn{1}{c|}{ Exemplos observados } \\
\hline \multirow{5}{*}{$\begin{array}{l}\text { Educação } \\
\text { Ambiental }\end{array}$} & Concepções & $\begin{array}{l}\text { Cuidar do meio ambiente; preservar; como preservar; } \\
\text { conservar se não um dia acaba; dar valor ao que você tem; } \\
\text { reciclar; aprender sobre o meio ambiente; educar a natureza; } \\
\text { atividades com a comunidade (SOS Mata Atlântica) }\end{array}$ \\
\cline { 2 - 4 } & Importância & $\begin{array}{l}\text { Para elas colaborarem e ajudarem o meio ambiente; para preservar } \\
\text { a natureza; para a gente viver (vai ter mais árvores; oxigênio) }\end{array}$ \\
\hline & Concepções & $\begin{array}{l}\text { Ser legal com o próximo; cidade; respeitar; } \\
\text { população; os deveres de uma população }\end{array}$ \\
\cline { 2 - 3 } & $\begin{array}{l}\text { Relação com } \\
\text { a Educação } \\
\text { Ambiental }\end{array}$ & $\begin{array}{l}\text { A educação ambiental é para se conscientizar, para cuidar } \\
\text { da natureza. Ter respeito pela natureza entra na parte da } \\
\text { cidadania, entra nos deveres que você tem; da maneira que } \\
\text { o ser humano vai ter seus direitos e deveres, a natureza } \\
\text { também; na cidadania, você tem seus deveres e, como é } \\
\text { uma educação ambiental, você tem o dever de cuidar; se o } \\
\text { cidadão tem seus direitos, por que as plantas também não? }\end{array}$ \\
\hline
\end{tabular}

Figura 1- Categorias, subcategorias e exemplos observados nos resultados da monitoria para os alunos do $7^{\circ}$ ano do ensino fundamental II.

Fonte: Pesquisa de campo.

Elaboração dos autores.

\begin{tabular}{|c|c|c|}
\hline Categorias & Subcategorias & Exemplos observados \\
\hline \multirow{4}{*}{$\begin{array}{l}\text { Motivo da } \\
\text { Visita }\end{array}$} & $\begin{array}{l}\text { Complementação } \\
\text { dos Estudos } \\
\text { Escolares }\end{array}$ & $\begin{array}{l}\text { A gente estava vendo negócio de plantas; teve prova } \\
\text { ontem; podia ter feito isso antes da prova, né? }\end{array}$ \\
\hline & $\begin{array}{l}\text { Visita Cultural, } \\
\text { (aquisição de novos } \\
\text { conhecimentos) }\end{array}$ & $\begin{array}{l}\text { Para conhecer a floresta; nunca visitei aqui; visitei } \\
\text { quando era pequenininha; vim conhecer. }\end{array}$ \\
\hline & Lazer & É lindo; é legal. \\
\hline & Outros & A professora pediu; porque, se não viesse, não ganharia nota \\
\hline \multirow{3}{*}{$\begin{array}{l}\text { Conteúdo } \\
\text { do Jardim }\end{array}$} & Flora & Plantas; flores; briófitas; plantas \\
\hline & Fauna & Pessoas; cobras; aves; patinhos \\
\hline & Ambiente & Natureza; muito verde; biodiversidade \\
\hline \multirow{4}{*}{$\begin{array}{l}\text { Atividades } \\
\text { do Jardim } \\
\text { Botânico }\end{array}$} & Conservação & $\begin{array}{l}\text { Cuidam do jardim, dos animais; cuidam da } \\
\text { vegetação; ajudam a manter o espaço }\end{array}$ \\
\hline & Pesquisa & Estudam biologia; pesquisa \\
\hline & Educação & Tem instrutor \\
\hline & Outros & Constroem, trabalham \\
\hline Plantas & Estrutura & Raiz; caule; folha; pétalas; flor; fruto; semente \\
\hline \multirow{2}{*}{ Flores } & $\begin{array}{l}\text { Importância } \\
\text { para a Planta }\end{array}$ & A "boniteza"; atrair os insetos; reprodução \\
\hline & $\begin{array}{l}\text { Importância para } \\
\text { os Animais }\end{array}$ & Alimentar; o pólen; o néctar \\
\hline \multirow{2}{*}{$\begin{array}{l}\text { Educação } \\
\text { Ambiental }\end{array}$} & Concepções & $\begin{array}{l}\text { Respeitar o meio ambiente; aprender sobre ele; } \\
\text { preservar; conhecer para depois preservar }\end{array}$ \\
\hline & Importância & $\begin{array}{l}\text { Educação pra vida; para a conscientização das } \\
\text { pessoas; para conservar; para preservar }\end{array}$ \\
\hline
\end{tabular}

(continua...) 
(...continuação)

\begin{tabular}{|c|l|l|}
\hline Categorias & Subcategorias & \multicolumn{1}{c|}{ Exemplos observados } \\
\hline \multirow{5}{*}{ Cidadania } & Concepções & $\begin{array}{l}\text { Respeitar o próximo; você respeitar mais; dia a dia; } \\
\text { respeito da sociedade; respeito pelo ambiente }\end{array}$ \\
\cline { 2 - 3 } & $\begin{array}{l}\text { Relação com } \\
\text { a Educação } \\
\text { Ambiental }\end{array}$ & $\begin{array}{l}\text { Cidadania é o dever, são os deveres e direitos que você } \\
\text { tem na sociedade, envolve a educação ambiental, a } \\
\text { preservação do meio ambiente; educação ambiental é o } \\
\text { fato de preservar; respeito das pessoas pela natureza }\end{array}$ \\
\hline
\end{tabular}

Figura 2 - Categorias, subcategorias e exemplos observados nos resultados da monitoria para os alunos do $3^{\circ}$ ano do ensino médio.

Fonte: Pesquisa de campo.

Elaboração dos autores.

\section{CONSIDERAÇÕES FINAIS}

Conclui-se que as escolas participantes das atividades foram ao Jardim Botânico com objetivos definidos, principalmente relacionados ao ensino desenvolvido na escola. Apesar de muitas escolas não reconhecerem a importância do espaço não formal, as unidades estudadas demonstraram expectativas positivas em relação ao auxílio fornecido pelo espaço para as atividades escolares. Sabe-se que poucas escolas visitam espaços extraclasse como um recurso educacional e de apoio para o ensino formal; contudo, diversos estudos constatam a importância do desenvolvimento da educação ambiental em todos os espaços e níveis sociais.

No caso da pesquisa relatada, o contato proporcionado pelo espaço não formal possibilitou o vivenciamento prático de informações trabalhadas na escola de uma forma desfragmentada. Por meio da investigação e observação do ambiente, os alunos foram capazes de discutir o conteúdo do jardim e as principais funções da instituição. A atividade coletiva proporcionada pela atividade possibilitou a construção conjunta dos conhecimentos e o trabalho em equipe pelos alunos. Durante as dinâmicas, os alunos utilizaram conhecimentos prévios adquiridos no próprio processo de aprendizagem para o esclarecimento e resolução dos problemas propostos, processo construtivista que foi além da recepção passiva de informações.

Houve a interação entre conceitos prévios adquiridos de maneira informal e formal para a assimilação de informações no espaço não formal do Jardim. Com base na observação de variados objetos de estudo, os alunos puderam associar informações visuais locais e conhecimentos prévios na argumentação, reflexão da questão abordada e no desenvolvimento de uma aprendizagem significativa.

Em relação à educação ambiental e à cidadania, os alunos demonstraram conhecimentos indiretamente relacionados à alfabetização científica e às relações entre a ciência, a tecnologia, a sociedade e o meio ambiente, o que representa o importante impacto do campo CTSA no processo de aprendizagem dos alunos estudados.

As atividades desenvolvidas no Jardim Botânico de São Paulo foram importantes para o desenvolvimento da educação ambiental com os alunos da escola 
básica. Muitos deles não possuíam conhecimentos suficientes que permitissem a reflexão e, consequentemente, a sua conscientização para a conservação e preservação do meio ambiente. Pelos conhecimentos prévios dos alunos, conceitos foram reforçados e outros (re)formulados, o que possibilitou um trabalho de alfabetização científica e de sensibilização dos visitantes.

No entanto, até que ponto a sensibilização e a capacitação dos alunos foram eficientes para uma possível conscientização? Como os conhecimentos conquistados pelos alunos no Jardim Botânico estão influenciando o processo educativo formal desenvolvido nas escolas? Da mesma maneira que os conhecimentos prévios dos alunos obtidos pela educação formal foram importantes para o ensino não formal mediado, informações que foram assimiladas no processo não formal provavelmente estão sendo importantes para o ensino formal desenvolvido pelas escolas.

São necessárias outras atividades e pesquisas que reforcem essa iniciativa e que comprovem de que maneira os resultados conquistados estão sendo aproveitados no ambiente escolar.

\section{REFERÊNCIAS}

Ab’Saber, Aziz Nacib. (Re)conceituando educação ambiental. In: Magalhães, Luiz Edmundo. A questão ambiental. 1. ed. São Paulo: Terra Graph, 1994.

Barbosa, Luiz Mauro; Ротомati, Adriana; Peccinini, Alejandro Alvarado. O PEFI: histórico e legislação. In: Bicudo, Denise de Campos; Fortı, Maria Cristina; Bicudo, Carlos Eduardo de Mattos. Parque Estadual das Fontes do Ipiranga (PEFI): unidade de conservação que resiste à urbanização de São Paulo. São Paulo: Secretaria do Meio Ambiente do Estado de São Paulo, 2002. p. 16-28.

Bardin, Laurence. Análise de conteúdo. Lisboa: Edições 70, 1977.

Brasil. Ministério da Saúde. Plano Nacional de Saúde e Ambiente no Desenvolvimento Sustentável. Brasília, DF, 1995.

Cerati, Tania Maria; Rocha, Mário Borges da; Roberti, Fátima Aparecida Viveiros Valente; Costa, Roberto Dell'Aglio Dias da; Festa, Mário; Perez, Zuleica Maria de Lisboa; SABIÁ, Irene Rosa. O PEFI como instrumento de educação. In: Bicudo, Denise de Campos; ForTi, Maria Cristina; Bicudo, Carlos Eduardo de Mattos. Parque Estadual das Fontes do Ipiranga (PEFI): unidade de conservação que resiste à urbanização de São Paulo. São Paulo: Secretaria do Meio Ambiente do Estado de São Paulo, 2002.p. 298-317.

Dias, Genebaldo Freire. Educação ambiental: princípios e práticas. 4. ed. São Paulo: Gaia, 1994.

FArias, Carmen Roselaine de Oliveira; Freitas, Denise. Educação ambiental e relações CTS: uma perspectiva integradora. Ciência \&̊ Ensino, Campinas: gepCE/FE/UNICAMP, GPEAG/IG/UNICAMP; Florianópolis: DICITE/UFSC, v. 1, p. 1, nov. 2007.

FÁvero, Osmar. Educação não formal: contextos, percursos e sujeitos. Educação छ̋ Sociedade, Campinas: CEDES ,v. 28, n. 99, p. 614-617, maio/ago. 2007. 
Fernandes, Amélia João; Reis, Luiz Augusto Mota; Carvalho, Adilson. Caracterização do meio físico. In: Bicudo, Denise de Campos; ForTi, Maria Cristina; Bicudo, Carlos Eduardo de Mattos. Parque Estadual das Fontes do Ipiranga (PEFI): unidade de conservação que resiste à urbanização de São Paulo. São Paulo: Ed. Secretaria do Meio Ambiente do Estado de São Paulo, 2002. p. 50-62.

Franco, Maria Laura Puglisi Barbosa. Análise de conteúdo. Brasília: Plano Editora, 2003. Franzolin, Fernanda; Bizzo, Nelio. Conceitos de biologia em livros didáticos de educação básica e na academia: uma metodologia de análise. In: EnContro NACIONAL de Pesquisa em Educação em Ciências, 6., 2007, Florianópolis. Anais... Belo Horizonte: ABRAPEC, 26 nov./1 dez. 2007. p. 1.041-1.052.

Gil-Pérez, Daniel; Vilches, Amparo. La contribución de la ciencia a la cultura ciudadana. Cultura y Educación, Salamanca: Fundación Infancia y Aprendizaje, v. 16, n. 3, p. 259-272, out. 2004.

Giondan, André; Vecchi, Gérard. As origens do saber: das concepções dos aprendentes aos conceitos científicos. 2. ed. Porto Alegre: Artes Médicas, 1996.

Gohn, Maria da Glória. Educação não formal, participação da sociedade civil e estruturas colegiadas nas escolas. Ensaio: Avaliação e Políticas Públicas em Educação, Rio de Janeiro: Fundação CESGRANRIO, v. 14, n. 50, p. 27-38, jan./mar. 2006.

Guimarães, Mauro. A dimensão ambiental na educação. Campinas: Papirus, 1995.

Invernizzi, Noela; FraGA, Lais. Estado da arte na educação em ciência, tecnologia, sociedade e ambiente no Brasil. Ciência छ' Ensino, Campinas: gepCE/FE/UNICAMP, GPEAG/IG/UNICAMP; Florianópolis: DICITE/UFSC, v. 1, n. especial, p.1-3, nov. 2007.

Malafaia, Guilherme; Rodrigues, Aline Sueli de Lima. Uma reflexão sobre o ensino de ciências no nível fundamental da educação. Ciência E Ensino, Campinas: gepCE/ FE/UNICAMP, GPEAG/IG/UNICAMP; Florianópolis: DICITE/UFSC, v. 2, n. 2, p. 1-9, jun. 2008.

Marandino, Martha; Ianelli, Isabela Tacito. Modelos de educação em ciências em museus: análise da visita orientada. Ensaio Pesquisa em Educą̧ão em Ciências, Belo Horizonte: UFMG, v. 14, n. 1, p. 17-33, jan./abr. 2012.

Mersenas, Paulo. Aspectos metodológicos da pesquisa empírica: a contribuição de Paulo Freire. Revista Espaço Acadêmico, Maringá: Universidade Estadual de Maringá, n. 78, p. 1, nov. 2007. Disponível em: <http://www.espacoacademico.com.br/078/78meksenas. htm>. Acesso em: 25 jul. 2010.

Moreira, Marco Antonio. Aprendizagem significativa: um conceito subjacente. In: Encuentro Internacional sobre el Aprendizaje Significativo, 1997, Burgos. Actas... Burgos: Universidad de Burgos, 15-19, set. 1997. p. 19-44.

Morin, Edgar. Planetarización y crisis de la humanidad. Educación 2001, DF-México, n. 152, p. 34-38,jan. 2008. Disponível em: < http://www.multiversidadreal.org/noticias68. asp >. Acesso em: 29 maio 2010. 
Oliveira, Roni Ivan Rocha de; Gastal, Maria Luiza de Araújo. Educação formal fora da sala de aula - olhares sobre o ensino de ciências utilizando espaços não formais. In: Encontro Nacional de Pesquisadores em Educação em Ciências, 7., 2009, Florianópolis. Anais... Florianópolis: ABRAPEC, 8-14, nov. 2009. Disponível em: <http://www.foco.fae.ufmg.br/viienpec/index.php/enpec/viienpec/paper/ viewFile/1674/193>. Acesso em: 10 maio 2012.

Pelicioni, Maria Cecília Focesi. Educação ambiental, qualidade de vida e sustentabilidade. Saúde e Sociedade, São Paulo: Universidade de São Paulo, v. 7, n. 2, p. 19-31, nov. 1998.

Pereira, Tânia Elizette Barata; Sauma Filho, Michel. Educação ambiental: subsídios para a sensibilização de estudantes sobre a questão energética. In: EnContro NACionAL de Pesquisadores em Educação em Ciências, 5., 2005, Bauru. Anais... Bauru: ABRAPEC, nov./dez. 2005. Disponível em: < http://www.nutes.ufrj.br/abrapec/venpec/ conteudo/artigos/1/pdf/p837.pdf $>$. Acesso em: 12 fev. 2012.

PIno, Ivany Rodrigues (Coord.). 30 anos de Educação \& Sociedade. Educą̧ão छ̋ Sociedade, Campinas: CEDES, v. 29, n. 104, p. 641-644, out. 2008.

Pivelli, Sandra Regina Pardini; Kawasa ki, Clarice Sumi. Análise do potencial pedagógico de espaços não formais de ensino para o desenvolvimento da temática da biodiversidade e sua conservação. In: Encontro Nacional de Pesquisadores em Educação em Ciências, 5., 2005, Bauru. Anais... Bauru: ABRAPEC, nov./dez. 2005. Disponível em: <http://www.nutes.ufrj.br/abrapec/venpec/conteudo/artigos/1/pdf/ p674.pdf>. Acesso em: 8 fev. 2012.

Portela, Sérvio Túlio; Braga, Francisco de Assis; Ameno, Helena Alvim. Educação ambiental: entre a intenção e a ação. Revista Eletrônica do Mestrado em Educação Ambiental, Rio Grande: Universidade Federal do Rio Grande, v. 24, p. 331-340, jan./ jul. 2010. Disponível em: < http://www.remea.furg.br/edicoes/vol24/art22v24.pdf>. Acesso em: 10 nov. 2010.

Praia, João; Gil-Pérez, Daniel; Vilches, Amparo. O papel da natureza da ciência na educação para a cidadania. Ciência Ė Educação, Bauru: UNESP, v. 13, n. 2, p. 141156, set. 2007.

Ricardo, Elio Carlos. Educação CTSA: obstáculos e possibilidades para sua implementação no contexto escolar. Ciência E Ensino, Campinas: gepCE/FE/ UNICAMP, GPEAG/IG/UNICAMP; Florianópolis: DICITE/UFSC, v. 1, n. especial, nov. 2007.

SAntos, Maria Eduarda V. M. Una educación para el desarrollo sostenible. Linhas de força de um projecto educativo que insere a construção da cidadania na construção do saber científico. In: Congreso Internacional sobre Investigación en la Didáctica de las Ciencias, 7., 2005, Granada. Anais... Granada: UAB, 7-10, set. 2005. p. $1-4$. 
São Paulo. Secretaria do Meio Ambiente. Conselho de Defesa do Parque Estadual das Fontes do Ipiranga. 2010. Disponível em: <http://www.condepefi.sp.gov.br/instituicoes/ instituicoes_fontes_ipiranga.htm >. Acesso em: 15 set. 2010.

SAto, Michèle. Debatendo os desafios da educação ambiental. Revista Eletrônica do Mestrado em Educação Ambiental, Rio Grande: Universidade Federal do Rio Grande; FURG, v. 1, p. 14-33, 2001. Disponível em: < http://www.cpd1.ufmt.br/gpea/pub/ DesafiosEA.pdf >. Acesso em: 12 out. 2009.

Vieira, Valéria; Bianconi, Monique Lucia; Dias, Monique. Espaços não formais de ensino e o currículo de ciências. Ciência e Cultura, Campinas: SBPC, v. 57, n. 4, out./ dez. 2005.

Vilches, Amparo; Solbes, Jordi; Gil-Pérez, Daniel. Alfabetización científica para todos contra ciencia para futuros científicos. Alambique, Barcelona: IRIF, v. 41, p. 8998, 2004.

Willison, Julia. Educação ambiental em jardins botânicos: diretrizes para o desenvolvimento de estratégias individuais. Rio de Janeiro: Rede Brasileira de Jardins Botânicos, 2003.

\section{SOBRE OS AUTORES}

Hebert Kondrat é mestrando em biodiversidade vegetal e meio ambiente pelo Instituto de Botânica de São Paulo.

E-mail: hebberkon@hotmail.com

Maria Delourdes Maciel é doutora em educação pela Pontifícia Universidade Católica de São Paulo (PUC-SP). Professora titular III da Universidade Cruzeiro do Sul.

E-mail: delourdes.maciel@gmail.com

Recebido em dezembro de 2011

Aprovado em setembro de 2012 


\section{RESUMOS/ABSTRACTS/RESUMENS}

\section{HEBERT KONDRAT E MARIA DELOURDES MACIEL}

\section{Educação ambiental para a escola básica: contribuições para o desenvolvimento da cidadania e da sustentabilidade}

A concretização de uma alfabetização científica em ambientes formais e não formais de educação é uma necessidade para a formação e manutenção de uma sociedade sustentável. Objetivou-se estudar os conhecimentos prévios de alunos da educação básica relacionados a temas ambientais e tomá-los como base para realizar atividades de educação ambiental. Foram efetivadas monitorias no espaço do Jardim Botânico de São Paulo para alunos do $7^{\circ}$ ano do ensino fundamental e do $3^{\circ}$ ano do ensino médio. Trabalharam-se ao longo das visitas questões relacionadas ao meio ambiente e à cidadania. A pesquisa foi qualitativa, do tipo observação participante, com registro da fala dos estudantes durante as atividades de monitoria. Categorias e subcategorias foram destacadas nas respostas dos alunos, assim como suas reflexões relacionadas à ciência, à tecnologia, à sociedade e ao meio ambiente, conquistadas ao longo das atividades de educação ambiental.

Palavras-chave: alfabetização científica; educação não formal; meio ambiente; Jardim Botânico.

\section{Environmental education for primary and secondary education: contributions to citizenship and sustainability development}

Building and maintaining a sustainable society requires the achievement of scientific literacy in formal and non-formal education. We aimed to study the prior knowledge of early childhood, primary and secondary students about environmental issues and to use that knowledge as the basis for conducting environmental education activities. Those activities took place at the Botanical Garden of São Paulo for students in the 7th grade of primary education and 3rd year of secondary education. During the visits, we worked on issues related to the environment and citizenship. It was a qualitative study, with participant observation and the record of students' speech during the activities. Categories and subcategories were highlighted in the students'answers, as well as their reflections on science, technology, society and environment, obtained during the environmental education activities.

Keywords: scientific literacy; non-formal education; environment; Botanical Garden.

Educación ambiental a la escuela básica: contribuciones al desarrollo de la ciudadanía y la sostenibilidad

La aplicación de una alfabetización cientifica en ambientes formales y no formales de educación es una necesidad para la formación y mantenimiento de una sociedad sostenible. Este trabajo tenía como objetivo estudiar los conocimientos previos de los estudiantes de educación básica para las cuestiones ambientales, y adoptarlos para llevar a cabo actividades de educación ambiental. Se realizaron monitorias en el Jardín Botánico de São Paulo para los alumnos de $7^{\circ}$ grado de la escuela primaria y $3^{\text {er }}$ grado de la escuela secundaria. Se trabajaron, a lo largo de las visitas, 
cuestiones relacionadas con medio ambiente y la ciudadania. La investigación fue cualitativa, observación de tipo participante, se grabó el discurso de los estudiantes durante las actividades monitoreadas. Categorías y subcategorias se destacaron en las respuestas de los estudiantes, asi como sus reflexiones, relacionadas con la ciencia, tecnología, sociedad y ambiente; todo ello se logró durante las actividades de educación ambiental.

Palabras clave: alfabetización cientifica; educación no formal; medio ambiente; Jardín Botánico. 